DOI: 10.12731/2070-7568-2020-4-226-254

УДК 334.7

\author{
СИСТЕМА ПОДДЕРЖКИ \\ ПРИНЯТИЯ РЕШЕНИЙ (СППР) В СЛОЖНЫХ \\ ПРЕДПРИНИМАТЕЛЬСКИХ СТРУКТУРАХ \\ КАК РАЗВИВАЮЩИЙСЯ ИНСТРУМЕНТ УПРАВЛЕНИЯ
}

\title{
Цовма Д.В.
}

Информационная поддержка принятия стратегических решений в группах компаний может быть, с одной стороны, очень актуальной ввиду большого числа учитываемых параметров, с другой сторонь, вполне продуктивной ввиду объективной измеримости этих параметров. В отличие от традиционных подходов к экономическому анализу самостоятельного хозяйствующего субъекта, дочерние и зависимые общества (ДЗО) оцениваются и с точки зрения их влияния на материнскую компанию и группу компаний $в$ целом. Поэтому автор исследования сформировал набор показателей, который можно перегруппировывать для различных аналитических и прогностических иелей, тем самым создав и апробировав авторскую методику оченки деятельности ДЗО. Рекомендации в области стратегического управленческого решения даются на основании анализа сочетания полученных оченок. Качество прогностической функиии СППР ГК проиллюстрировано соотнесением рекомендаций в области стратегического управленческого решения со стоимостью дочерних компаний в последующие годы.

Цель - сформировав некоторую общую методологию, разработать технологию поддержки принятия стратегических управленческих решений в сложных предпринимательских образованиях типа «группа компаний».

Метод или методология проведения работы: использованы комплексный и системный подходы, методы структурно-функционального исследования, сравнительного анализа, динамических 
рядов, графический метод и методы экономико-математического моделирования и др.

Результаты: методика оценки деятельности ДЗО и информационной поддержки принятия стратегических управленческих решений в группах компаний.

Область применения результатов: полученнье результать могут быть использованы крупными российскими компаниями с развитой сетью ДЗО при принятии стратегических решений, а также при разработке собственных корпоративных нормативных актов (стандартов, регламентов и т.п.) в области поддержки решений.

Ключевые слова: система поддержки принятия решений; стратегические решения; дочерние и зависимые общества; группа компаний; устойчивость.

\section{DECISION SUPPORT SYSTEM (DSS) \\ IN COMPLEX ENTREPRENEURIAL STRUCTURES \\ AS A DEVELOPING MANAGEMENT TOOL}

\section{Tsovma D.V.}

Information support for making strategic decisions in groups of companies can be, on the one hand, very relevant due to the large number of parameters taken into account, on the other hand, it is quite productive due to the objective measurability of these parameters. Unlike traditional approaches to the economic analysis of an independent business entity, subsidiaries and dependent companies (SDCs) are also evaluated in terms of their impact on the parent company and the group of companies as a whole. Therefore, the author of the study has formed a set of indicators that can be regrouped for various analytical and prognostic purposes, thereby creating and testing the author's methodology for assessing the activities of subsidiaries and affiliates. Recommendations in the field of strategic management decisions are given based on the analysis of the combination of the estimates obtained. The quality 
of the predictive function of the GKDSS is illustrated by the correlation of recommendations in the field of strategic management decisions with the value of subsidiaries in subsequent years.

Purpose is to form some general methodology, to develop a technology to support the adoption of strategic management decisions in complex entrepreneurial formations such as a "group of companies".

Methodology: integrated and systematic approaches, methods of structural and functional research, comparative analysis, time series, graphical method and methods of economic and mathematical modeling, etc.

Results: a methodology for assessing the activities of subsidiaries and affiliates and information support for making strategic management decisions in groups of companies.

Practical implications: the results obtained can be used by large Russian companies with a developed network of subsidiaries and affiliates in making strategic decisions, as well as in developing their own corporate regulations (standards, regulations, etc.) in the field of decision support.

Keywords: decision support system; strategic decisions; subsidiaries and dependent companies; group of companies; sustainability.

\section{Введение}

Многие российские группы компаний с финансовой точки зрения обладают достаточно высоким запасом прочности, а значительный объем обеспеченности запасами природных ресурсов позволяет с оптимизмом смотреть на их долгосрочную перспективу. При этом для них сегодня очень важно, с одной стороны, поддерживать высокую эффективность основного производственного блока - предприятий базовой отрасли, структурные элементы материнской компании, с другой стороны - обеспечивать безубыточность вспомогательного, обслуживающего и социального блоков, представленных сетью дочерних и зависимых обществ (ДЗО). Особенно это важно на фоне падения платежеспособного спроса населения, являющегося целевым сегментом для бизнесов ДЗО.

Если в состав группы входят разные по возрасту непрофильные предприятия, большая часть из которых ведет свою историю из 
60-70-х гг. прошлого века и ориентирована не на развитие бизнеса в условиях рынка, а на «оправдание» текущих затрат и обоснование увеличения «помощи-подпитки» от материнской компании, возникает необходимость сбалансировать информационно-аналитическую систему стратегического управления группой компаний с тем, чтобы планомерно и целенаправленно повышать эффективность всех предприятий группы и стоимость компании в целом. А компания может этого добиться в современной экономической среде только при условии качественной информационной поддержки стратегических решений, построенной на основе многокритериальной оценки деятельности множества хозяйствующих субъектов. В данном случае под качеством мы понимаем возможность у руководства одновременно обладать своевременной, достоверной и однозначно интерпретируемой информацией о текущей ситуации и способность анализировать всевозможные причинно-следственные связи, формулировать выводы и принимать качественные стратегические управленческие решения.

\section{Методология и методика исследования}

На основе хорошо известных концепций (концепция стратегического управления) и подходов (системный, процессный подходы) можно описать управление группой компаний в виде достаточно широкого перечня управленческих компетенций.

Целью функционирования Системы поддержки принятия стратегических инвестиционных решений для группы компаний (СППР ГК или Decision Support System in Group Company) является обеспечение лиц, принимающих подобные решения в многокритериальных условиях сложных предпринимательских образований, данными для повышения качества управления группой компаний. Информационная система, основанная на многокритериальных оценках, должна, на наш взгляд, удовлетворять следующим требованиям помимо тех, которые традиционно предъявляются к СППР:

1. Наличие возможности многомерного статистического анализа многопараметрических данных. 
2. Гибкость настройки запросов и широкий диапазон настроек отчетов.

3. Наличие возможности интерактивной визуализации отчетов (визуализация как аналитический инструмент!).

4. Гибкость контрольных панелей.

5. Высокая производительность обработки данных.

6. Наличие прогностических инструментов.

7. Наличие инструментов использования в перспективе искусственного интеллекта.

СППР ГК в ходе настоящего исследования была представлена пятью модулями, четыре из которых отвечают за управление в конкретном ДЗО, а один - за общую консолидацию в рамках управления группой ДЗО.

Модуль 1. Адекватность ДЗО корпоративному управлению группы компаний. Предметом оценки и анализа выступают преимущественно качественные показатели, которые объясняют причины возникновения актива у ПАО Татнефть, анализируют историю важнейших в деятельности ДЗО решений, эффективность текущей стратегии и высшего руководства. Среди основных показателей, которые могут помочь достоверно оценить данный аспект, следует отметить:

1.1. Год основных инвестиций, на основании которого определяется продолжительность истории актива в качестве ДЗО в составе группы. Основанием для включения данного показателя могут служить следующие соображения. Чем старше дочернее общество, чем продолжительнее корпоративные отношения, тем в данном случае прочнее хозяйственные связи между материнской компанией и ДЗО и соответственно более болезненной и рисковой будет продажа актива или его ликвидация. Предлагается для условий ПАО Татнефть следующая градация: до 2000 года; 2000-2010 годы; 2011-2015 годы; после 2015 года.

1.2. Формат создания актива. Создать «с нуля» или купить действующее предприятие - это всегда вопрос эффективности решения собственника. В случае с группой компаний этот вопрос, как правило, решается в пользу приобретения 100\% или меньшей доли 
участия в готовом бизнесе. Для создания нового актива материнской компании требуется серьезная аргументация с обоснованием плохо прогнозируемых денежных потоков и окупаемости долгосрочных инвестиций в условиях слабо предсказуемых условий и рисков. Поэтому градация показателей оценки корпоративного управления в ПАО Татнефть может быть следующее: создание, приобретение $100 \%$ актива; приобретение доли участия в активе.

1.3. Доля ПАО в капитале ДЗО (или доля материнской компании в капитале дочернего или зависимого общества, рассчитывается в процентах). Доля участия в капитале согласно законодательству и здравому смыслу определяет степень влияния и роль материнской компании в управлении ДЗО вплоть до наложения вета на решения органов управления. Зависимость доли участия на степень влияния в данном случае является прямой, поэтому градация значений показателя может быть следующей: 100\%; 50-99,9\%; 25-50\%; менее 25\%.

1.4. Доля доходов ДЗО, формируемая в основной ЦСЦ ПАО. Это показатель, который призван отражать «встроенность» дочернего или зависимого общества в основную цепочку создания ценности материнской компании, т.е. другими словами, это показатель уровня вертикальной интеграции в группе компаний. Показатель (в процентах) для конкретной ДЗО за отчетный период может быть рассчитан следующим образом:

$$
\text { Доля Д3О } \text { цсц ПАО }=\frac{\text { Доходы ДЗО }}{\text { Выручка ДЗО }+ \text { Проч. доходы ДЗО }} \times 100 \% \text {. }
$$

В идеале необходимо учитывать только те договоры с ПАО, платежи по которым включаются в себестоимость ПАО!!! Градация фактических значений показателя будет следующая: 100\%; 50$99,9 \% ; 25-49,9 \%$; менее $25 \%$.

1.5. Форма инвестиций. Гражданское законодательство РФ $\Phi^{1}$ предусматривает следующие основные конструкции, применяемые при слиянии компаний: реорганизация в форме слияния, создание партнерами бизнес-единицы (хозяйственного общества, товарищества

${ }^{1}$ Гражданский кодекс Российской Федерации (в частности, статья 57) 
или партнерства), увеличение уставного капитала, приобретение «блокирующей» доли участия в бизнес-единице по гражданскоправовому договору. В случае с группой компаний, каковой была определена совокупность юридически самостоятельных, но... зависимых друг от друга хозяйствующих субъектов, объединенных централизованной системой контроля..., наиболее распространенными случаями в практике российских компаний являются третий и четвертый. Увеличение уставного капитала (в АО через дополнительный выпуск акций, в ООО - через вклад третьего лица в уставный капитал). Процедура включает в себя принятие органом управления компании решения об увеличении уставного капитала, передачу имущества в оплату доли участия (при необходимости регистрацию перехода права собственности), внесение изменений в устав компании и их регистрацию в налоговом органе. Четвертый вариант удобен для портфельного инвестирования. Для условий ПАО Татнефть будем рассматривать следующую градацию: прямой выкуп доли участия; передача имущества в оплату доли участия.

1.6. Основной аргумент сделки. Предлагается поделить возможные аргументы для создания (приобретения) актива на рыночные и нерыночные. К рыночным следует отнести трансфертные цены, контроль управления в рамках ВИНК, расширение рынка. При этом контроль управления социальной сферой и политические аргументы следует отнести к нерыночным. Преобладание нерыночных соображений при приобретении и содержании актива расценивается как достаточно рисковый фактор для стратегического развития группы компаний даже в специфических экономических условиях современной России.

1.7. Уровень корпоративной стандартизации, определяемый долей локальных нормативных актов ДЗО, согласованных и утвержденных в материнской компании (в процентах). Локальные корпоративные акты закрепляют индивидуально-правовой статус организации, они принимаются органами управления организации. При принятии локальных корпоративных актов органы управления организации, будучи свободными в определении содержания 
локальных актов, но должны учитывать, требования нормативных актов и стандартов корпоративного централизованного регулирования. При принятии локальных актов ДЗО необходимо учитывать распределение нормотворческой компетенции между органами управления материнской компании, если таковое имеется. В случае с ПАО Татнефть, где в целом по материнской компании уровень стандартизации достаточно высок, градация показателя должна быть следующей: $100 \% ; 75-99,9 \% ; 25-49,9 \%$; менее $25 \%$.

1.8. Дополнительные инвестиции в ДЗО с момента основных инвестиций. Показатель может быть оценен и как абсолютное значение инвестиций (в этом случае ограничиваются ресурсы сравнительного анализа), и как относительная величина, представляющая собой дробь, где в качестве числителя - сумма дополнительных инвестиций со стороны ПАО за весь период отношений, в знаменателе - величина основных инвестиций при создании (приобретении) актива:

$$
\kappa_{\text {доп.инв. }}=\frac{\sum \text { Доп. инв. }}{\text { Осн. инв. }}
$$

1.9. Оценка качества управления материальными (внеоборотными за минусом нематериальных) активами, выраженная индексом изменения (темпом роста) величины материальных активов с момента основных инвестиций (в процентах):

$$
I_{\text {ма }}=\frac{\mathrm{BOA}_{t}-\mathrm{HMA}_{t}}{\mathrm{BOA}_{t 0}-\mathrm{HMA}_{t 0}} .
$$

Высокое качество управления в данном аспекте будет рассматриваться в случае, если значение индекса больше 1.

1.10. Оценка эффективности руководителя ДЗО, выраженная опережением темпами роста ПТ на предприятии темпов роста годовой зарплаты руководителя за 5 лет, позволяет оценить качество кадровых решений топ-менеджмента материнской компании. Высокие эффективность и качество решений предполагаются при условии, если опережение зафиксировано (т.е. отношение темпов роста больше 1).

1.11. Дата последнего стратегического анализа, позволяющая определить период с момента такого анализа, важна как показатель 
заинтересованности руководства материнской компании в долгосрочном и эффективном развитии актива. Определение периодичности стратегического анализа - вопрос не такой однозначный, как может показаться на первый взгляд. Казалось бы, стратегический анализ необходим в качестве эмпирической базы для разработки стратегии на следующие 5, 7, 10, 20 и т.д. лет. Но он не менее необходим и для контроля реализации стратегии, ее корректировки в условиях существенных изменений организационной среды. Предлагается градировать показатель следующим образом: до года; от года до 3 лет; от 3 до 5 лет; более 5 лет.

1.12. Результаты последнего стратегического анализа ДЗО могут рассматриваться как результаты портфельного анализа группы компаний. Многочисленны методики стратегического анализа (от матриц БКГ и МакКинзи [1] до анализа цепочки создания стоимости компании и отрасли. Обобщив методики и немного перефразировав используемые в них термины, мы предлагаем следующие результаты стратегического анализа дочерних компаний: перспективное; нейтральное; неперспективное.

Модуль 2. Управление операционной деятельностью ДЗО. Предметом оценки и анализа опять же выступают преимущественно качественные показатели, которые помогают оценить базовый аспект, основу получения добавленной стоимости дочернего общества. В МСФО под операционной деятельностью понимается основная деятельность компании, а также прочая деятельность, исключая финансовую и инвестиционную [2]. В РФ определение основного и дополнительных видов экономической деятельности используют Общероссийский классификатор видов экономической деятельности [3] (ОКВЭД 2), входящий в состав Национальной системы стандартизации Российской Федерации. ОКВЭД 2, кроме прочего, используется при решении задач, связанных с определением основного и дополнительных видов экономической деятельности, осуществляемых хозяйствующими субъектами. От кода предприятия по ОКВЭД зависит и формирование учетной политики, правила формирования выручки, себестоимости, налогооблагаемой базы по налогу 
на прибыль, и пр. Но в нашем случае операционная деятельность ДЗО показательна с точки зрения оценки перспектив использования нефинансовых инструментов повышения стоимости актива: за счет расширения клиентской базы, за счет воспроизводства и укрепления производственного потенциала, за счет балансирования и оптимизации продуктового портфеля, за счет повышения эффективности использования трудовых ресурсов и пр.

2.1. Этап жизненного цикла отрасли или продукта (услуги) в регионе. Определение стадии развития рынка для организации необходимо для того, чтобы иметь базу сравнения частных показателей операционной деятельности организации и общих по отрасли (региону). В данном случае чрезмерное дробление этапов и стадий жизненного цикла может привести к неточному определению и ошибкам отнесения тех или иных тенденций к признакам стадий. Поэтому предлагается выделить только 4 основных этапа: детство, юность, зрелость, старость.

2.2. Сбалансированность продуктового портфеля - показатель, под которым предлагается понимать положительное и растущее значение рентабельности продуктового портфеля, рассчитанного как средняя рентабельностей отдельных продуктов (услуг), взвешенная по стоимостному объему реализации этих продуктов:

$$
R_{\text {порт }}=\frac{\sum_{i=1}^{n} Q_{i} \times R_{i}}{\sum_{i=1}^{n} Q_{i}} .
$$

где $Q_{i}$ - объем продукции $i$-ого вида в стоимостных единицах;

$R_{i}$ - рентабельность $i$-ого продукта (услуги), которая рассчитывается аналогично рентабельности продаж:

$$
R_{i}=\frac{\left(\mathrm{B}_{i}-\mathrm{Cc}_{i}\right)}{\mathrm{B}_{i}}
$$

Показатель может быть рассчитан как средняя рентабельностей отдельных продуктов (услуг), взвешенная по натуральному объему реализации этих продуктов. В этом случае для приведения объемов широкой номенклатуры товаров к сопоставимому виду используется обычный метод условных эквивалентов.

Если показатель за три последних года имеет только отрицательные значения и при этом позитивный тренд не выражен, ситуацию 
можно расценить как несбалансированный продуктовый портфель. В случае устойчивого роста положительных значений показателя - ситуация рассматривается как сбалансированный продуктовый портфель. Промежуточная ситуация так и рассматривается - 50/50.

2.3. Механизм ценообразования в компании предлагается оценивать с позиции наличия рыночных основ. Если в ДЗО применяется преимущественно рыночное ценообразование (или на основе маркетинга) на большинство продуктов и услуг, т.е. главным ориентиром для предприятия при установления оптовых/ розничных цен являются цены конкурентов, обеспечивающие тяготение конъюнктуры к ситуации рыночного равновесия. С точки зрения группы компаний такое дочернее общество менее подвержено рискам политических решений, имеет бОльшую независимость, более адаптивно к изменениям внешней среды. Поэтому предлагается следующая градация показателя: рыночное (на основе маркетинга), издержки плюс норма прибыли и трансфертное (на покрытие затрат).

2.4. Динамика производства в натуральном выражении оценивается по темпам роста (индексам) производства по основным группам товаров (услуг). Отрицательная динамика на протяжении трех лет расценивается как негативная ситуация.

2.5. Относительная производительность труда, выраженная отношением производительности труда работников ДЗО в отчетном периоде к аналогичному среднеотраслевому показателю. Производительность труда на предприятии рассчитывается по методике Росстата [4]. Очевидно, что благоприятной рассматривается ситуация, когда показатель принимает значения больше 1.

2.6. Конкурентная позиция предприятия на локальном (региональном) рынке - одна из важнейших характеристик организационной среды. Предлагается оценивать по следующему показателю:

$$
\text { КП }=\frac{\text { Доля }}{100 \%} \times N_{\mathrm{K}}
$$

где первый множитель - рыночная доля ДЗО, приведенная к долям единиц;

$$
N_{\text {к }} \text { - число прямых конкурентов. }
$$


Значение показателя больше 1 свидетельствует о лидирующем положении ДЗО на локальном (региональном) рынке.

2.7. Оценка адекватности производственной стратегии должна опираться на важное методологическое положение о сути производственной стратегии. По мнению отдельных авторов [5], она состоит в балансировании производственных мощностей, рабочей силы и объема выпускаемой продукции. Согласно вышесказанному, принято выделять следующие виды производственных стратегий:

- стратегия преследования (удовлетворения спроса), которая состоит в производстве объема, необходимого на данный момент (при постоянстве запасов обеспечивается объем производства, соответствующий спросу на рынке);

- стратегия равномерного производства, при которой объем производства находится на постоянном уровне в течение длительного времени (уровень соответствует среднему уровню спроса на продолжительном горизонте измерений);

- стратегия субподряда, предполагающая выпуск продукции на минимально допустимом уровне (недостаток поставки в отдельные моменты обеспечивается за счет привлечения субподрядчиков);

- гибридная стратегия, состоящая в комбинации выше приведенных походов.

Для ДЗО, на наш взгляд, любая из первых трех производственных стратегий может быть оправдана. Четвертая стратегия не является эффективной в условиях небольшого предприятия и содержит в себе массу рисков нехватки или неэффективного использования производственных мощностей.

Соответствие производственной стратегии ДЗО внешним и внутренним хозяйственным условиям может быть оценено экспертами как полное, 50/50 и несоответствие.

2.8. Резервы активизации (расширения) операционной деятельности преимущественно подразумевают возможности увеличения масштабов производства и могут оцениваться экспертами как имеются и отсутствуют. 
2.9. Зона безопасности предприятия (в процентах к фактической выручке) важна и как самостоятельный показатель, и во взаимосвязи с предыдущим показателем, т.к. показывает, насколько можно сократить объем продаж без риска получения убытков, а также насколько принципиальным для предприятия является увеличение постоянных затрат, необходимое для расширения производства. Достаточность зоны безопасности зависит от многих факторов: отрасли (менее фондоемкие отрасли должны демонстрировать большую зону безопасности), этапа жизненного цикла организации (молодое и растущее предприятие может позволить себе меньшую зону безопасности), общая стратегия предприятия (при реализации наступательной стратегии может быть оправдана меньшая зона безопасности) и т.д. Поэтому представляется целесообразным оценивать даже не изменение показателя во времени, а отклонение зоны безопасности ДЗО от зоны безопасности материнской компании:

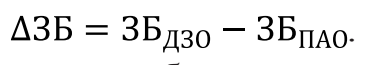

Отрицательное отклонение будет свидетельствовать об относительной рисковости актива, а усугубление этой тенденции на 3-5-летнем цикле должно серьезным образом насторожить топменеджмент группы компаний.

Модуль 3. Текущий финансовый анализ ДЗО. Предметом оценки и анализа в данном случае выступают преимущественно количественные показатели, при накоплении достаточной массы которых кроме аналитической функции начнут выполнять прогностическую функцию. Сегодня методики финансового анализа предполагают расчет около 100 в той или иной мере взаимосвязанных показателей. Руководствуясь принципом оптимальности предлагается рассчитывать и анализировать ограниченный набор показателей.

3.1. Показатели ликвидности баланса важны как оценка возможности покрытия активами ДЗО его обязательств.

3.1.1. Общий показатель ликвидности баланса предприятия, показывающий отношение суммы всех взвешенных по значимости ликвидных средств предприятия к сумме всех так же взвешенных платежных обязательств (краткосрочных, долгосрочных, средне- 
срочных). Расчетная формула имеет традиционный вид [6]. Нормальным считается значение коэффициента от 1,5 до 2,5 в зависимости от отрасли экономики.

3.1.2. Коэффициент обеспеченности собственными средствами отражает долю собственных оборотных средств во всех оборотных активах предприятия. Этот показатель важен в качестве оценки финансового управления ДЗО, т.к. показывает, способно ли данное предприятие осуществлять финансирование текущей деятельности только собственными оборотными средствами или же может потребоваться помощь со стороны, в том числе, со стороны материнской компании. Согласно законодательству [7] нормальное значение коэффициента обеспеченности собственным оборотным капиталом находится выше, чем 0,1.

3.2. Финансовая устойчивость в современной теории и практике экономического анализа рассматривается как важнейших фактор стабильности предприятия.

3.2.1. Коэффициент финансового левериджа представляет собой соотношение заемного и собственного капитала организации. В российской практике оптимальным считается значение коэффициента финансового левериджа, равное 1. Допустимым может быть и значение до 2. Наиболее распространенным значением коэффициента в мировой практике является 1,5.

3.2.2. Коэффициент автономии в данном случае важен как индикатор финансовой независимости ДЗО. Общепринятое нормальное значение коэффициента автономии в российской практике: 0,5 и более. В развитых экономиках до $30-40 \%$ собственного капитала считается допустимым.

3.3. Деловая активность - это характеристика качества управления активами или скорость проведения финансово-хозяйственных операций. Для ее оценки выбран коэффициент оборачиваемости активов, который свидетельствует о том, сколько раз совершается полный цикл производства и обращения. Нормативное значение показателя опять же зависит от отрасли. Поэтому безусловно стоит рассматривать показатель в динамике, а также, по возможности, - сравнивать значение показателя в ДЗО с аналогичными значениями прямых конкурентов. 
3.4. Рентабельность продаж (ROS) как показатель финансовой результативности деятельности организации, показывающий какая часть выручки организации приходится на прибыль, имеет различные варианты расчета и анализа. В СППР ГК предлагается рассчитывать, учитывать при принятии решений и прогнозировании показатель операционной рентабельности или в рамках РСБУ рентабельность продаж, рассчитанную по прибыли от продаж. Этот показатель позволит исключить прочую (в том числе, финансовую) деятельность из числа факторов, влияющих на эффективность деятельности ДЗО. Оптимальное значение показателя во многом определяется отраслью предприятия. Поэтому, как и во многих иных случаях, целесообразно оценивать динамику показателя или сравнивать со среднеотраслевыми значениями.

3.5. В СППР ГК логичнее использовать показатель рентабельности операционных активов, под которым мы понимаем активы, непосредственно задействованные предприятием в обычной (операционной) деятельности.

3.6. Издержкоемкость - показатель, не особенно распространенный в практике микроэкономического анализа. Тем не менее, его использование при проведении сравнительного анализа уровня затрат по группе многопрофильных компаний может дать неплохие результаты. Он представляет собой отношение общей суммы затрат на производство и реализацию продукции (или себестоимости) к стоимости произведенной продукции в действующих ценах (или выручке). Безусловно значение показателя издержкоемкости как минимум должен быть меньше 1. Любое сильное отклонение частного показателя по конкретному ДЗО от общего показателя по группе компаний или резкий рост показатель (особенно с сильным приближением к единице) должно привлечь внимание и аналитиков, и лиц, принимающих решение.

Модуль 4. Стоимость компании и бизнеса. Международный комитет по стандартам оценки выделяет [8] подхода к оценке любого актива: сравнительный (direct market comparison approach), доходный (income approach) и затратный (cost approach). Первый основан 
на сравнении объекта оценки с аналогами, в отношении которых можно говорить о достоверности информации о ценах. Второй - на определении ожидаемых доходов от использования объекта оценки. Третий - на определении затрат, необходимых для полного воспроизводства (восстановления) объекта оценки.

4.1. Эффективность использования имущества ДЗО. В стоимость имущества в СППР ГК будем включать все внеоборотные активы ДЗО (включая нематериальные активы), запасы и денежные средства. Показателем эффективности использования имущества следует считать годовой совокупный (по всем видам деятельности) денежный поток, приходящийся на 1 тыс. руб. стоимости имущества:

$$
K_{\text {имущ }}=\frac{C F_{\Sigma}}{(\mathrm{BA}+3+\text { ДС })} .
$$

Оптимальные в данном случае значения могут быть определены в процессе апробации. Но, вероятнее всего, целесообразно оценивать динамику показателя или сравнивать со средним значением по группе компаний.

4.2. Прогноз денежного потока на 5 лет. Ключевыми параметрами реализации данной прогнозной модели являются свободный денежный поток и коэффициент дисконтирования. Прогнозирование денежных потоков может проводиться методом линейной регрессии. В качестве объекта прогнозирования может выступать прибыль до налогообложения или денежный поток, формируемый чистой прибылью, амортизацией и сальдо по инвестиционной деятельности, оборотному капиталу и инвестициям. Метод дисконтирования денежных потоков основывается на том, что стоимость активов сегодня равняется скорректированной текущей стоимости будущих денежных потоков, которые принесут активы. Предметом окончательной оценки является индекс роста годового денежного потока через 5 лет относительно текущего момента. Шкала точных значений может быть сформирована в процессе апробации.

4.3. Общая оценка стоимости ДЗО. Ввиду того, что бОльшая часть ДЗО - непубличные компании, любые методы оценки стоимости 
фирмы (и ее бизнеса), преимущественно основанные на рыночной цене акций, в данном случае не применимы. Наиболее объективным в определении рыночной стоимости бизнеса непубличной компании представляется доходный подход. Хотя сегодня более или менее активно публикуются результаты апробации новых, например, гибридного затратно-доходного подхода [9] к оценке стоимости бизнеса. В основе доходного подхода заложен принцип ожидания: любой актив, приобретаемый с целью извлечения доходов, будет стоить ровно столько, сколько прибыли он принесет в будущем с учетом фактора времени. Оценка может быть произведена и с точки зрения стоимости всей фирмы, с учетом как собственного, так и заемного капитала, и с учетом стоимости только собственного капитала. В первом случае используется денежный поток фирмы (FCFF), а во втором - денежный поток на собственный капитал (FCFE). В финансовом моделировании, в частности в DCF модели, чаще всего используется FCFF, а именно UFCF (Unlevered Free Cash Flow) или свободный денежный поток компании до вычета финансовых обязательств. В качестве ставки дисконтирования можно использовать показатель WACC (Weighted Average Cost of Capital) - средневзвешенная стоимость капитала.

4.4. Эффективность последних инвестиций призвана свидетельствовать об успехах ДЗО в области реализации инвестиционных проектов. В качестве основных показателей оценки предлагается использовать два: чистый дисконтированный доход и индекс доходности инвестиций. В случае отсутствия данных можно использовать накопленное за последние 3-5 лет сальдо от инвестиционных операций.

4.5. Наличие резервов роста у рынка (отрасли), в котором (которой) действует ДЗО, можно определить по индексу объемов рынка:

$$
I_{\mathrm{p}}=\frac{Q_{t-1}}{Q_{t}}
$$

При этом объемы рынка несложно определить на основе данных официальной статистики по произведенному ВВП или по индексу физического объема произведенных продукции и услуг по ОКВЭД, в том числе, по отдельным регионам. 
4.6. Для оценки стратегических перспектив развития предприятия полезно также оценивать его инновационный потенциал, представляющий собой сложную комбинацию разнообразных имеющихся ресурсов (технологии, кадры, оборудование и пр.). Именно разнообразие таких ресурсов создает сложность их совместной оценки. Поэтому для обеспечения однозначности результата оценки можно оценить долю нематериальных активов в стоимости всех внеоборотных активов. Для интерпретации полученных значений следует ориентироваться на среднеотраслевые значения.

Модуль 5. Управление проектами. Перспективы развития ДЗО зависят не только от внешних более или менее благоприятных условий и имеющегося у предприятия потенциала, но и от того, насколько, прежде всего, менеджмент сможет использовать возможности. Поэтому способность управлять динамическими характеристиками, такими как умение ставить и достигать конкретных целей, руководить командой, контролировать исполнение бюджета, планировать время и пр. должна оцениваться в рамках отдельного модуля.

5.1. Количество проектов в ДЗО (на дату) может свидетельствовать как о проектной активности и инициативности менеджмента, так и об уровне доверия высшего руководство группы компаний в его адрес. Абсолютное значение (в единицах проектов без учета бюджета, сроков проекта) можно сравнить со средним значением показателя по всем ДЗО. Действующие проекты в материнской компании учитывать не следует.

5.2. Доля успешных проектов за последние 5 лет (в процентах) может быть определена как отношение числа успешно завершенных проектов в срок и без выделения дополнительного бюджета к общему числу проектов, запущенных в ДЗО:

$$
\text { Доля }_{\text {уп }}=\frac{N_{\text {уп }}}{N_{\Sigma}} \times 100 \% .
$$

5.3. Влияние текущих (завершенных) проектов ДЗО на чистую прибыль ГК может быть определено как процент отклонения текущей чистой прибыли группы компаний от смоделированной вели- 
чины чистой прибыли в случае, если бы проект ДЗО, например, в текущем году, не был реализован.

Модуль 6 Консолидация.

6.1. Доля перспективных ДЗО в общем количестве ДЗО.

6.2. Влияние ДЗО на капитализацию ПАО (ГК).

6.3. Отсутствие фактов отрицательного влияния ДЗО на репутацию ГК.

\section{Использование результатов исследования}

Приведенные выше показатели имеют различную природу. Среди них присутствуют как качественные, так и количественные показатели. Ряд показателей измеряется (то есть фиксируется и учитывается например, год создания и выручка), ряд показателей - рассчитывается более или менее сложным способом (например, коэффициенты финансового состояния). Ряд показателей может быть оценена только экспертным способом (например, адекватность общей стратегии).

Между всеми этими показателями должен быть найден компромисс. Для этого была применена шкала с тремя уровнями оценки: хорошо (зеленый), удовлетворительно (желтый), плохо (красный). В зависимости от попадания фактического значения показателя в определенную ячейку формируется сводный столбец интерпретации значений за конкретный год.

Аналогичным образом формируются столбцы за любое количество периодов (лет). В итоге может быть получено 3-цветное «поле», позволяющее сразу увидеть и воспринять преобладающий цвет, цветовые кластеры, их локализацию по горизонтали (в динамике) и по вертикали (по модулям оценки). То есть расчет показателей на примере конкретных ДЗО уже позволяет обогатить стратегический анализ предприятий научно обоснованными оценками, расчет этих же показателей за 5-летний период позволяет выявлять устойчивые тенденции в развитии предприятий и повышать качество планов и прогнозов.

Система поддержки принятия решений в группе компаний не должна ограничиваться расчетом, анализом показателей и визуализацией полученных результатов. Ее смысл заключается в том, чтобы, во- 
первых, существенно (как минимум, кратно) ускорить сбор и обработку достоверной информации, а во-вторых, использовать инструменты, «подсказывающие» решения с учетом целеполагания всей группы.

До сих пор в исследовании речь шла преимущественно об измерителях деятельности дочерних и зависимых обществ (ДЗО) в составе сложных предпринимательских структур (ответ на вопрос «как»). Но главной целью настоящего исследования является ответ на вопрос «зачем», «с какой целью». То есть необходимо помнить, что конкретные результаты измерений и анализа должны быть правильно и продуктивно использованы в принятии решений. Расчетно-аналитические инструменты помогают оценить существующее положение дел с точки зрения влияния ДЗО на стоимость ГК, на ее долгосрочное устойчивое развитие и стимулирование экономического интереса собственников - акционеров. Но сам механизм «перевода» количественных значений в управленческие действия стало возможным описать только в ходе исследования.

Проанализировав то, к каким выводам могут привести расчетноаналитические процедуры, был разработан «треугольник балансировки ДЗО» (рис.).

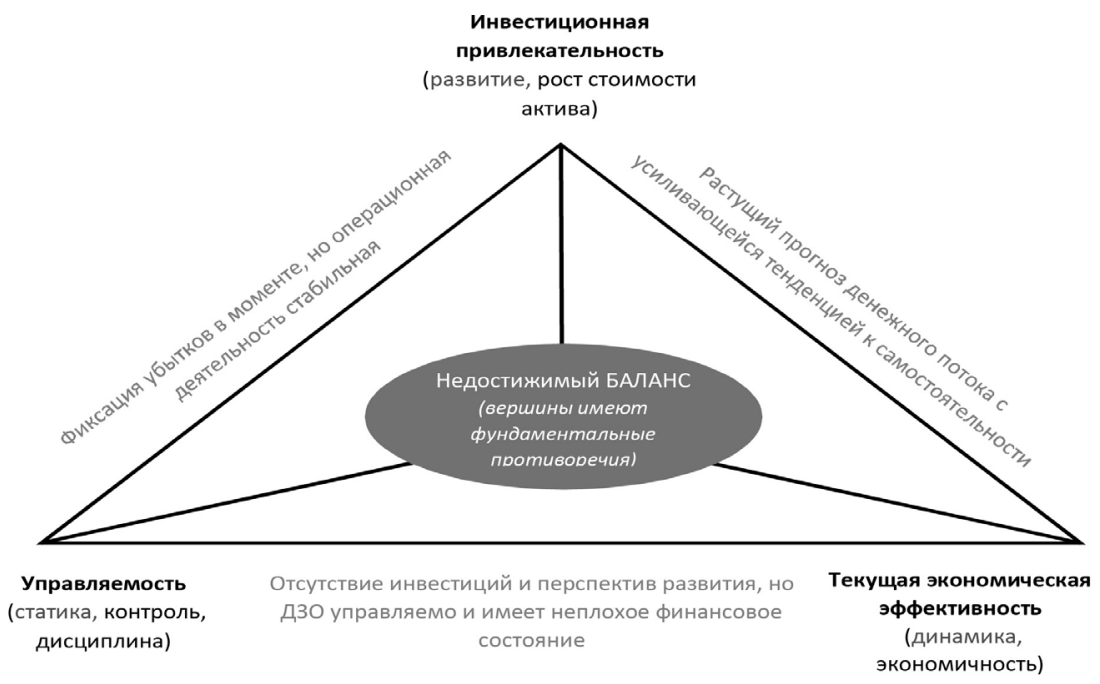

Рис. Треугольник балансировки ДЗО в ГК 
На трех вершинах треугольника размещаются три противоположные по отношению друг к другу состояния предприятий-ДЗО.

1 состояние «Управляемость» характеризуется стабильно положительными показателями статики, попаданием их значений в зеленую зону. С точки зрения взаимодействия с материнской компанией (ядром ГК) эти предприятия отличает высокая исполнительская дисциплина, их главная цель - четко исполнять поручения корпоративного центра, или, другими словами, избегать претензий со стороны корпоративного центра.

2 состояние «Текущая экономическая эффективность» характеризуется стабильно положительными показателями динамики. С точки зрения взаимодействия с материнской компанией эти предприятия финансово прозрачны и эффективны, любая поддержка со стороны корпорации дает отдачу.

3 состояние «Инвестиционная привлекательность» характеризуется стабильно положительными показателями развития. С точки зрения взаимодействия с материнской компанией эти предприятия - самый ценный ликвидный актив корпорации, хотя и вполне беспокойный, т.к. может тяготеть к автономии.

Для отнесения состояния конкретного предприятия-ДЗО к тому или иному типу необходимо было перегруппировать показатели из первоначальных пяти модулей в новые три.

Безусловно, эти три состояния в чистом виде встречаются редко, если не сказать, что не встречаются никогда. Равно как и на $100 \%$ сбалансированная ситуация (устойчивости) в реальности, скорее всего, невозможна. Но преобладание положительных черт того или иного состояния (т.е. фокусировка на одном-двух состояниях из возможных трех): управляемости, текущей экономической эффективности или долгосрочной инвестиционной привлекательности, - все это может служить методическим подспорьем и в анализе и диагностике, и в прогнозировании и регулировании, и в самом широком смысле - в управлении ДЗО. Результаты апробации методики и информационной системы поддержки решений на других предприятиях ГК Татнефть приведены в приложении. 


\section{Заключение (результаты апробации)}

В таблице 1 представлены сводные итоговые результаты апробации СППР ГК на примере 16 ДЗО в Группе Татнефть. Как видно из приведенных данных, система не только позволяет сделать выводы и способствует принятию обоснованных решений относительно конкретных ДЗО, но и помогает до определенной степени точности выявить общую закономерность в развитии всей сети ДЗО. Так, несложно было установить, что всего 5 компаний из 16 получили общую оценку «выше средней». Эта общая оценка дается на момент проведения анализа (в нашем случае - на конец 2017 года, хотя в конечном программном продукте может быть реализован режим «на день запроса»).

Треть компаний ожидаемо не достигают половины от максимально возможного уровня, т.к. в России формирование групп компаний далеко не всегда диктовалось рыночными мотивами или соображениями экономической эффективности.

Наибольшие оценки с существенным отрывом получили преимущественно показатели модуля «Корпоративное управление». Такое преобладание свидетельствует о том, что каждое дочернее общество - это, прежде всего, часть большой корпорации, и уж потом все остальное: самостоятельное юридическое лицо, представитель отрасли или географического рынка и т.д.

Таблииа 1.

\section{Сводная итоговая таблица результатов апробации СППР ГК} на примере 16 ДЗО в Группе Татнефть

\begin{tabular}{|c|c|c|c|c|c|}
\hline $\begin{array}{c}\text { Наименование } \\
\text { ДЗО }\end{array}$ & $\begin{array}{c}\text { Общая (коли- } \\
\text { чественная) } \\
\text { оценка на мо- } \\
\text { мент анализа } \\
\text { (максимум - } \\
4000)\end{array}$ & $\begin{array}{c}\text { Модуль } \\
\text { оценки с } \\
\text { наибольши- } \\
\text { ми перспек- } \\
\text { тивами }\end{array}$ & $\begin{array}{c}\text { Модуль } \\
\text { оценки с } \\
\text { наибольши- } \\
\text { ми уязвимо- } \\
\text { стями }\end{array}$ & $\begin{array}{l}\text { Позиция } \\
\text { ДЗО в } \\
\text { «треу- } \\
\text { гольнике } \\
\text { баланси- } \\
\text { ровки» }\end{array}$ & $\begin{array}{c}\text { Рекомендации } \\
\text { в области } \\
\text { стратегиче- } \\
\text { ского управ- } \\
\text { ленческого } \\
\text { решения }\end{array}$ \\
\hline 1 & 2 & 3 & 4 & 5 & 6 \\
\hline $\begin{array}{l}\text { ООО «Тат- } \\
\text { нефть-Самара» } \\
\text { (геологораз- } \\
\text { ведка) }\end{array}$ & 2350 & $\begin{array}{c}\text { Корпоратив- } \\
\text { ное управ- } \\
\text { ление }\end{array}$ & $\begin{array}{c}\text { Текущий } \\
\text { финансовый } \\
\text { анализ }\end{array}$ & $\begin{array}{l}\text { динамика- } \\
\text { развитие }\end{array}$ & $\begin{array}{c}\text { Сохранить } \\
\text { и развивать } \\
\text { актив }\end{array}$ \\
\hline
\end{tabular}




\begin{tabular}{|c|c|c|c|c|c|}
\hline $\begin{array}{c}\text { Наименование } \\
\text { ДЗО }\end{array}$ & $\begin{array}{c}\text { Общая (коли- } \\
\text { чественная) } \\
\text { оценка на мо- } \\
\text { мент анализа } \\
\text { (максимум - } \\
4000)\end{array}$ & $\begin{array}{c}\text { Модуль } \\
\text { оценки с } \\
\text { наибольши- } \\
\text { ми перспек- } \\
\text { тивами }\end{array}$ & $\begin{array}{c}\text { Модуль } \\
\text { оценки с } \\
\text { наибольши- } \\
\text { ми уязвимо- } \\
\text { стями }\end{array}$ & $\begin{array}{l}\text { Позиция } \\
\text { ДЗО в } \\
\text { «треу- } \\
\text { гольнике } \\
\text { баланси- } \\
\text { ровки» }\end{array}$ & $\begin{array}{c}\text { Рекомендации } \\
\text { в области } \\
\text { стратегиче- } \\
\text { ского управ- } \\
\text { ленческого } \\
\text { решения }\end{array}$ \\
\hline 1 & 2 & 3 & 4 & 5 & 6 \\
\hline $\begin{array}{l}\text { ОАО «Калм- } \\
\text { нефтегаз» (гео- } \\
\text { логоразведка) }\end{array}$ & 1650 & нет & $\begin{array}{c}\text { Текущий } \\
\text { финансовый } \\
\text { анализ }\end{array}$ & $\begin{array}{l}\text { динамика- } \\
\text { развитие }\end{array}$ & $\begin{array}{c}\text { Продавать или } \\
\text { реструктури- } \\
\text { зировать }\end{array}$ \\
\hline $\begin{array}{l}\text { ОАО «ТАНЕ- } \\
\text { КО» (производ- } \\
\text { ство нефтепро- } \\
\text { дуктов) }\end{array}$ & 3050 & $\begin{array}{c}\text { Операцион- } \\
\text { ная деятель- } \\
\text { ность } \\
\text { Стоимость } \\
\text { бизнеса }\end{array}$ & $\begin{array}{c}\text { Текущий } \\
\text { финансовый } \\
\text { анализ }\end{array}$ & $\begin{array}{l}\text { динамика- } \\
\text { развитие }\end{array}$ & $\begin{array}{c}\text { Сохранить } \\
\text { актив }\end{array}$ \\
\hline $\begin{array}{l}\text { ООО } \\
\text { «Татнефть-АЗС } \\
\text { Центр» (опто- } \\
\text { вая торговля } \\
\text { моторным то- } \\
\text { пливом) }\end{array}$ & 1800 & $\begin{array}{c}\text { Корпоратив- } \\
\text { ное управ- } \\
\text { ление }\end{array}$ & $\begin{array}{c}\text { Операцион- } \\
\text { ная деятель- } \\
\text { ность } \\
\text { Текущий } \\
\text { финансовый } \\
\text { анализ }\end{array}$ & развитие & $\begin{array}{c}\text { Сохранить } \\
\text { актив, но из- } \\
\text { менить стра- } \\
\text { тегию }\end{array}$ \\
\hline $\begin{array}{l}\text { ООО «Про- } \\
\text { цессинговый } \\
\text { центр» (про- } \\
\text { цессинговое } \\
\text { обслуживание) }\end{array}$ & 1600 & $\begin{array}{c}\text { Корпоратив- } \\
\text { ное управ- } \\
\text { ление }\end{array}$ & $\begin{array}{c}\text { Операцион- } \\
\text { ная деятель- } \\
\text { ность }\end{array}$ & статика & $\begin{array}{c}\text { Сохранить } \\
\text { и развивать } \\
\text { актив }\end{array}$ \\
\hline $\begin{array}{l}\text { ООО «УК } \\
\text { «Татнефть- } \\
\text { Нефтехим» } \\
\text { (управление } \\
\text { коммерческой } \\
\text { деятельностью } \\
\text { предприятий) }\end{array}$ & 1750 & $\begin{array}{c}\text { Корпоратив- } \\
\text { ное управ- } \\
\text { ление }\end{array}$ & $\begin{array}{c}\text { Операцион- } \\
\text { ная деятель- } \\
\text { ность } \\
\text { Текущий } \\
\text { финансовый } \\
\text { анализ }\end{array}$ & $\begin{array}{l}\text { статика- } \\
\text { динамика }\end{array}$ & $\begin{array}{c}\text { Сохранить } \\
\text { и развивать } \\
\text { актив }\end{array}$ \\
\hline $\begin{array}{l}\text { ОАО «НМЗ» } \\
\text { (производство } \\
\text { машин специ- } \\
\text { ального назна- } \\
\text { чения) }\end{array}$ & 1400 & $\begin{array}{c}\text { Корпоратив- } \\
\text { ное управ- } \\
\text { ление } \\
\text { Операцион- } \\
\text { ная деятель- } \\
\text { ность }\end{array}$ & $\begin{array}{c}\text { Текущий } \\
\text { финансовый } \\
\text { анализ }\end{array}$ & статика & $\begin{array}{c}\text { Продавать или } \\
\text { реструктури- } \\
\text { зировать }\end{array}$ \\
\hline $\begin{array}{l}\text { ООО «Нижне- } \\
\text { камская ТЭЦ» } \\
\text { (производство } \\
\text { электроэнергии } \\
\text { тепловыми } \\
\text { электростанци- } \\
\text { ями) }\end{array}$ & 1850 & $\begin{array}{c}\text { Корпоратив- } \\
\text { ное управ- } \\
\text { ление }\end{array}$ & $\begin{array}{c}\text { Операцион- } \\
\text { ная деятель- } \\
\text { ность } \\
\text { Текущий } \\
\text { финансовый } \\
\text { анализ }\end{array}$ & $\begin{array}{c}\text { статика- } \\
\text { динамика }\end{array}$ & $\begin{array}{c}\text { Сохранить } \\
\text { и развивать } \\
\text { актив }\end{array}$ \\
\hline
\end{tabular}




\begin{tabular}{|c|c|c|c|c|c|}
\hline $\begin{array}{c}\text { Наименование } \\
\text { ДЗО }\end{array}$ & $\begin{array}{c}\text { Общая (коли- } \\
\text { чественная) } \\
\text { оценка на мо- } \\
\text { мент анализа } \\
\text { (максимум - } \\
4000)\end{array}$ & $\begin{array}{c}\text { Модуль } \\
\text { оценки с } \\
\text { наибольши- } \\
\text { ми перспек- } \\
\text { тивами }\end{array}$ & $\begin{array}{c}\text { Модуль } \\
\text { оценки с } \\
\text { наибольши- } \\
\text { ми уязвимо- } \\
\text { стями }\end{array}$ & $\begin{array}{c}\text { Позиция } \\
\text { ДЗО в } \\
\text { «треу- } \\
\text { гольнике } \\
\text { баланси- } \\
\text { ровки» }\end{array}$ & $\begin{array}{c}\text { Рекомендации } \\
\text { в области } \\
\text { стратегиче- } \\
\text { ского управ- } \\
\text { ленческого } \\
\text { решения }\end{array}$ \\
\hline 1 & 2 & 3 & 4 & 5 & 6 \\
\hline $\begin{array}{l}\text { ООО «Тат- } \\
\text { нефть-Энергос- } \\
\text { быт» (распре- } \\
\text { деление элек- } \\
\text { троэнергии) }\end{array}$ & 2550 & $\begin{array}{c}\text { Текущий } \\
\text { финансовый } \\
\text { анализ } \\
\text { Стоимость } \\
\text { бизнеса }\end{array}$ & $\begin{array}{c}\text { Операцион- } \\
\text { ная деятель- } \\
\text { ность }\end{array}$ & $\begin{array}{l}\text { динамика- } \\
\text { развитие }\end{array}$ & $\begin{array}{c}\text { Сохранить } \\
\text { актив }\end{array}$ \\
\hline $\begin{array}{l}\text { ООО } \\
\text { «Татнефть- } \\
\text { УРС» (организа- } \\
\text { ция обществен- } \\
\text { ного питания) }\end{array}$ & 1400 & $\begin{array}{c}\text { Корпоратив- } \\
\text { ное управ- } \\
\text { ление } \\
\text { Операцион- } \\
\text { ная деятель- } \\
\text { ность }\end{array}$ & $\begin{array}{l}\text { Стоимость } \\
\text { бизнеса }\end{array}$ & статика & $\begin{array}{c}\text { Продавать или } \\
\text { реструктури- } \\
\text { зировать }\end{array}$ \\
\hline $\begin{array}{l}\text { ОАО «ТатНИ- } \\
\text { Инефтемаш» } \\
\text { (НИОКР) }\end{array}$ & 1350 & нет & $\begin{array}{c}\text { Текущий } \\
\text { финансовый } \\
\text { анализ } \\
\end{array}$ & статика & $\begin{array}{c}\text { Продавать или } \\
\text { реструктури- } \\
\text { зировать }\end{array}$ \\
\hline $\begin{array}{l}\text { ООО «НТЦ } \\
\text { Татнефть» } \\
\text { (НИОКР) }\end{array}$ & 1650 & $\begin{array}{c}\text { Корпоратив- } \\
\text { ное управ- } \\
\text { ление } \\
\text { Операцион- } \\
\text { ная деятель- } \\
\text { ность }\end{array}$ & $\begin{array}{l}\text { Стоимость } \\
\text { бизнеса }\end{array}$ & $\begin{array}{l}\text { динамика- } \\
\text { развитие }\end{array}$ & $\begin{array}{c}\text { Сохранить } \\
\text { и развивать } \\
\text { актив }\end{array}$ \\
\hline $\begin{array}{l}\text { ООО «Тат- } \\
\text { нефть-Актив» } \\
\text { (сдача имуще- } \\
\text { ства в аренду) }\end{array}$ & 2200 & $\begin{array}{c}\text { Корпоратив- } \\
\text { ное управ- } \\
\text { ление }\end{array}$ & $\begin{array}{c}\text { Текущий } \\
\text { финансовый } \\
\text { анализ }\end{array}$ & $\begin{array}{l}\text { динамика- } \\
\text { развитие }\end{array}$ & $\begin{array}{c}\text { Сохранить } \\
\text { актив }\end{array}$ \\
\hline $\begin{array}{l}\text { ООО «СКП } \\
\text { «Татнефть-Ак } \\
\text { Барс» (оптовая } \\
\text { торговля топли- } \\
\text { вом и деятель- } \\
\text { ность в области } \\
\text { спорта) }\end{array}$ & 2050 & $\begin{array}{l}\text { Стоимость } \\
\text { бизнеса }\end{array}$ & $\begin{array}{c}\text { Операцион- } \\
\text { ная деятель- } \\
\text { ность } \\
\text { Текущий } \\
\text { финансовый } \\
\text { анализ }\end{array}$ & статика & $\begin{array}{c}\text { Сохранить } \\
\text { актив, но из- } \\
\text { менить стра- } \\
\text { тегию }\end{array}$ \\
\hline $\begin{array}{l}\text { ООО «Теле- } \\
\text { компания } \\
\text { «Луч» (радио- } \\
\text { вещание и } \\
\text { телевидение) }\end{array}$ & 1900 & $\begin{array}{c}\text { Корпоратив- } \\
\text { ное управ- } \\
\text { ление }\end{array}$ & $\begin{array}{c}\text { Операцион- } \\
\text { ная деятель- } \\
\text { ность }\end{array}$ & $\begin{array}{c}\text { статика- } \\
\text { динамика }\end{array}$ & $\begin{array}{c}\text { Сохранить } \\
\text { актив, но из- } \\
\text { менить стра- } \\
\text { тегию }\end{array}$ \\
\hline $\begin{array}{l}\text { ООО «Снежин- } \\
\text { ка» (деятель- } \\
\text { ность рестора- } \\
\text { нов и доставка } \\
\text { продуктов } \\
\text { питания) }\end{array}$ & 1750 & $\begin{array}{c}\text { Корпоратив- } \\
\text { ное управ- } \\
\text { ление }\end{array}$ & $\begin{array}{c}\text { Операцион- } \\
\text { ная деятель- } \\
\text { ность } \\
\text { Текущий } \\
\text { финансовый } \\
\text { анализ }\end{array}$ & $\begin{array}{c}\text { статика- } \\
\text { динамика }\end{array}$ & $\begin{array}{c}\text { Продавать или } \\
\text { реструктури- } \\
\text { зировать }\end{array}$ \\
\hline
\end{tabular}


Наименьшие оценки с существенным отрывом получили преимущественно показатели модуля «Текущий финансовый анализ». Действительно, исследование показало, что многие ДЗО на протяжении, как минимум, пятилетнего периода демонстрируют чистый убыток, порой даже усугубляющийся с каждым годом. Зачастую небольшое, но положительное значение чистой прибыли достигается не за счет грамотного управления в ДЗО, а покрытия убытков материнской компанией. То есть, как минимум, две трети ДЗО как создавались в свое время (в 2000-е годы) без видимой рыночной аргументации, так и сегодня продолжают быть «плановоубыточными» и иметь своей главной целью «освоение» бюджетов и «оправдание» затрат.

Перегруппировав показатели оценки, по всем 16 ДЗО была получена картина несбалансированной фокусировки: у 8 из 16 - игнорирование управляемости, у 5 из 16 - «перекос» в сторону управляемости при игнорировании эффективности и инвестиционной привлекательности. Для обеспечения устойчивости предпринимательской системы половина ДЗО, демонстрирующие отсутствие управляемости как обязательной характеристики деятельности, это серьезный недостаток.

С одной стороны, мы отмечаем определенный инфантилизм дочерних обществ, с другой, - готовность к автономизации. Такая ситуация создает серьезные риски целостности и устойчивости системы.

Рекомендации в области стратегического управленческого решения даются на основании анализа сочетания полученных оценок. Пять из 16 ДЗО рекомендуется продать (ликвидировать) либо серьезным образом реструктуризировать. С нашей точки зрения, это тоже несколько больше, чем ожидалось (до апробации нормальным уровнем мы считали 10\% от общего числа ДЗО).

И, наконец, качество прогностической функции СППР ГК проиллюстрировано в таблице 2, где рекомендации в области стратегического управленческого решения 2018 года соотнесены со стоимостью дочерних компаний в 2019 году. 
Таблица 2.

Иллюстрация качества прогностической функции СППР ГК

\begin{tabular}{|c|c|c|c|}
\hline Наименование ДЗО & $\begin{array}{l}\text { Рекомендации в } \\
\text { области стратеги- } \\
\text { ческого управлен- } \\
\text { ческого решения }\end{array}$ & $\begin{array}{l}\text { Величина } \\
\text { и динами- } \\
\text { ка стоимо- } \\
\text { сти ДЗО }\end{array}$ & $\begin{array}{c}\text { Вывод о каче- } \\
\text { стве прогности- } \\
\text { ческой функции } \\
\text { СППР ГК }\end{array}$ \\
\hline 1 & 2 & 3 & 4 \\
\hline $\begin{array}{l}\text { ООО «Татнефть-Самара» } \\
\text { (геологоразведка) }\end{array}$ & $\begin{array}{l}\text { Сохранить и раз- } \\
\text { вивать актив }\end{array}$ & $\begin{array}{l}\text { Положи- } \\
\text { тельное } \\
\text { значение } \\
\text { растет }\end{array}$ & высокое \\
\hline $\begin{array}{l}\text { ОАО «Калмнефтегаз» (гео- } \\
\text { логоразведка) }\end{array}$ & $\begin{array}{c}\text { Продавать или } \\
\text { реструктуризиро- } \\
\text { вать }\end{array}$ & $\begin{array}{c}\text { Отрица- } \\
\text { тельное } \\
\text { значение } \\
\text { снижается }\end{array}$ & высокое \\
\hline $\begin{array}{l}\text { ОАО «ТАНЕКО» (произ- } \\
\text { водство нефтепродуктов) }\end{array}$ & Сохранить актив & $\begin{array}{l}\text { Положи- } \\
\text { тельное } \\
\text { значение } \\
\text { растет }\end{array}$ & высокое \\
\hline $\begin{array}{l}\text { ООО «Татнефть-АЗС } \\
\text { Центр» (оптовая торговля } \\
\text { моторным топливом) }\end{array}$ & $\begin{array}{c}\text { Сохранить актив, } \\
\text { но изменить стра- } \\
\text { тегию }\end{array}$ & $\begin{array}{l}\text { Положи- } \\
\text { тельное } \\
\text { значение } \\
\text { растет }\end{array}$ & высокое \\
\hline $\begin{array}{l}\text { ООО «Процессинговый } \\
\text { центр» (процессинговое } \\
\text { обслуживание) }\end{array}$ & $\begin{array}{c}\text { Сохранить и раз- } \\
\text { вивать актив }\end{array}$ & $\begin{array}{c}\text { Положи- } \\
\text { тельное } \\
\text { значение } \\
\text { растет }\end{array}$ & высокое \\
\hline $\begin{array}{l}\text { ООО «УК «Татнефть-Не- } \\
\text { фтехим» (управление ком- } \\
\text { мерческой деятельностью } \\
\text { предприятий) }\end{array}$ & $\begin{array}{l}\text { Сохранить и раз- } \\
\text { вивать актив }\end{array}$ & $\begin{array}{l}\text { Положи- } \\
\text { тельное } \\
\text { значение } \\
\text { растет }\end{array}$ & высокое \\
\hline $\begin{array}{l}\text { ОАО «НМЗ» (производство } \\
\text { машин специального на- } \\
\text { значения) }\end{array}$ & $\begin{array}{c}\text { Продавать или } \\
\text { реструктуризиро- } \\
\text { вать }\end{array}$ & $\begin{array}{c}\text { Положи- } \\
\text { тельное } \\
\text { значение } \\
\text { растет }\end{array}$ & $\begin{array}{c}\text { среднее, } \\
\text { изменена стра- } \\
\text { тегия }\end{array}$ \\
\hline $\begin{array}{l}\text { ООО «Нижнекамская ТЭЦ» } \\
\text { (производство электроэнер- } \\
\text { гии тепловыми электро- } \\
\text { станциями) }\end{array}$ & $\begin{array}{c}\text { Сохранить и раз- } \\
\text { вивать актив }\end{array}$ & $\begin{array}{l}\text { Положи- } \\
\text { тельное } \\
\text { значение } \\
\text { растет }\end{array}$ & высокое \\
\hline $\begin{array}{l}\text { ООО «Татнефть-Энер- } \\
\text { госбыт» (распределение } \\
\text { электроэнергии) }\end{array}$ & Сохранить актив & $\begin{array}{c}\text { Положи- } \\
\text { тельное } \\
\text { значение } \\
\text { снижается }\end{array}$ & среднее \\
\hline
\end{tabular}




\begin{tabular}{|c|c|c|c|}
\hline Наименование ДЗО & $\begin{array}{c}\text { Рекомендации в } \\
\text { области стратеги- } \\
\text { ческого управлен- } \\
\text { ческого решения }\end{array}$ & $\begin{array}{c}\text { Величина } \\
\text { и динами- } \\
\text { ка стоимо- } \\
\text { сти ДЗО }\end{array}$ & $\begin{array}{c}\text { Вывод о каче- } \\
\text { стве прогности- } \\
\text { ческой функции } \\
\text { СППР ГК }\end{array}$ \\
\hline 1 & 2 & 3 & 4 \\
\hline $\begin{array}{l}\text { ООО «Татнефть-УРС» (ор- } \\
\text { ганизация общественного } \\
\text { питания) }\end{array}$ & $\begin{array}{c}\text { Продавать или } \\
\text { реструктуризиро- } \\
\text { вать }\end{array}$ & $\begin{array}{c}\text { Положи- } \\
\text { тельное } \\
\text { значение } \\
\text { снижается }\end{array}$ & $\begin{array}{c}\text { высокое, } \\
\text { изменена стра- } \\
\text { тегия }\end{array}$ \\
\hline $\begin{array}{l}\text { ОАО «ТатНИИнефтемаш» } \\
\text { (НИОКР) }\end{array}$ & $\begin{array}{c}\text { Продавать или } \\
\text { реструктуризиро- } \\
\text { вать }\end{array}$ & $\begin{array}{c}\text { Положи- } \\
\text { тельное } \\
\text { значение } \\
\text { снижается } \\
\end{array}$ & высокое \\
\hline $\begin{array}{l}\text { ООО «НТЦ Татнефть» } \\
\text { (НИОКР) }\end{array}$ & $\begin{array}{c}\text { Сохранить и раз- } \\
\text { вивать актив }\end{array}$ & $\begin{array}{l}\text { Положи- } \\
\text { тельное } \\
\text { значение } \\
\text { растет } \\
\end{array}$ & высокое \\
\hline $\begin{array}{l}\text { ООО «Татнефть-Актив» } \\
\text { (сдача имущества в аренду) }\end{array}$ & Сохранить актив & $\begin{array}{c}\text { Положи- } \\
\text { тельное } \\
\text { значение } \\
\text { растет }\end{array}$ & высокое \\
\hline $\begin{array}{l}\text { ООО «СКП «Татнефть-Ак } \\
\text { Барс» (оптовая торговля } \\
\text { топливом и деятельность в } \\
\text { области спорта) }\end{array}$ & $\begin{array}{c}\text { Сохранить актив, } \\
\text { но изменить стра- } \\
\text { тегию }\end{array}$ & $\begin{array}{l}\text { Положи- } \\
\text { тельное } \\
\text { значение } \\
\text { растет }\end{array}$ & высокое \\
\hline $\begin{array}{l}\text { ООО «Телекомпания «Луч» } \\
\text { (радиовещание и телеви- } \\
\text { дение) }\end{array}$ & $\begin{array}{c}\text { Сохранить актив, } \\
\text { но изменить стра- } \\
\text { тегию }\end{array}$ & $\begin{array}{c}\text { Положи- } \\
\text { тельное } \\
\text { значение } \\
\text { растет } \\
\end{array}$ & высокое \\
\hline $\begin{array}{l}\text { ООО «Снежинка» (деятель- } \\
\text { ность ресторанов и достав- } \\
\text { ка продуктов питания) }\end{array}$ & $\begin{array}{c}\text { Продавать или } \\
\text { реструктуризиро- } \\
\text { вать } \\
\end{array}$ & $\begin{array}{c}\text { Значение } \\
\text { равно } 0\end{array}$ & высокое \\
\hline
\end{tabular}

Следовательно, целесообразность использования СППР ГК для целей прогнозирования является фактически доказанной.

\section{Список литературы}

1. Эванс В. Ключевые стратегические инструменты: 88 инструментов, которые должен знать менеджер. М.: Бином. Лаборатория знаний, 2015.

2. Отчет о движении денежных средств (IAS 7. Cash Flow Statements). URL: http://onoufriev.narod.ru/msfo/ias07.htm. (дата обращения: 27.06.2019 г.). 
3. Общероссийский классификатор видов экономической деятельности ОК 029-2014. URL: https://www.regfile.ru/okved2.html. (дата обращения: 15.07.2019 г.).

4. Об утверждении методик расчета показателей производительности труда предприятия, отрасли, субъекта Российской Федерации и методики расчета отдельных показателей Национального проекта «Производительность труда и поддержка занятости». Приказ от 28 декабря 2018 г. №748 Минэкономразвития РФ. URL: http://www.gks. ru/metod/naz-proekt/MET100005.pdf. (дата обращения: 15.07.2019 г.).

5. Авдеева Т.В. Развитие производственной стратегии промышленного предприятия. Автореферат диссертации на соискание ученой степени кандидата экономических наук. Саратов, 2010, 23 с.

6. Савицкая Г.В. Анализ хозяйственной деятельности предприятия. 4-е изд., перераб. и доп. Минск: ООО Новое знание, 2000.

7. Методические положения по оценке финансового состояния предприятий и установлению неудовлетворительной структуры баланса. Распоряжение Федерального управления по делам о несостоятельности (банкротстве) от 12.08.1994 г. № 31-р

8. Proposed New International Valuation Standards. Exposure Draft. International Valuation Standard Council, 2010.

9. Козырь Ю.В. Развитие методологии оценки стоимости бизнеса и компаний. Автореферат диссертации на соискание ученой степени доктора экономических наук. Москва, 2011. 59 с.

\section{References}

1. Evans V. Klyuchevye strategicheskie instrumenty: 88 instrumentov, kotorye dolzhen znat' menedzher [Key strategic tools: 88 tools that a manager should know]. M.: Binom. Knowledge laboratory, 2015.

2. Statement of cash flows (IAS 7. Cash Flow Statements). URL: http:// onoufriev.narod.ru/msfo/ias07.htm (accessed 27.06.2019).

3. All-Russian classifier of economic activities OK 029-2014. URL: https:// www.regfile.ru/okved2.html. (accessed 15.07.2019).

4. On approval of methods for calculating labor productivity indicators of an enterprise, industry, constituent entity of the Russian Federation and methods 
for calculating individual indicators of the National Project "Labor productivity and employment support". Order of December 28, 2018 No. 748 of the Ministry of Economic Development of the Russian Federation. URL: http:// www.gks.ru/metod/naz-proekt/MET100005.pdf. (accessed 15.07.2019).

5. Avdeeva T.V. Razvitie proizvodstvennoy strategii promyshlennogo predpriyatiy [Development of the production strategy of an industrial enterprise]. Saratov, 2010, $23 \mathrm{p}$.

6. Savitskaya G.V. Analiz khozyaystvennoy deyatel'nosti predpriyatiya [Analysis of the economic activity of the enterprise]. Minsk: LLC New Knowledge, 2000.

7. Methodological provisions for assessing the financial condition of enterprises and the establishment of an unsatisfactory balance sheet structure. Order of the Federal Office for Insolvency (Bankruptcy) from 12.08.1994, No. 31-r

8. Proposed New International Valuation Standards. Exposure Draft. International Valuation Standard Council, 2010.

9. Kozyr'Yu.V. Razvitie metodologii otsenki stoimosti biznesa i kompaniy [Development of methodology for assessing the value of businesses and companies]. Moscow, 2011.59 p.

\section{ДАННЫЕ ОБ АВТОРЕ}

\section{Цовма Денис Владимирович}

Публичное акциионерное общеество «Татнефть» имени В.Д. Шашина

ул. Ленина, 75, г. Альметьевск, 420450, Российская Федерация tsovma@tatneft.ru

\section{DATA ABOUT THE AUTHOR}

\section{Tsovma Denis Vladimirovich}

TATNEFT named after V.D. Shashina Public Joint Stock Company 75, Lenin Str., Almetyevsk, 420450, Russian Federation tsovma@tatneft.ru

ORCID: 0000-0002-1266-5195

Scopus Author ID: 57205198775 